\title{
Mechanical Activation of Chemical Process
}

\author{
Czesław Kajdas \\ Institute of Chemistry in Płock, Warsaw University of Technology, Warsaw, Poland \\ Email: ckajdas@pw.plock.pl
}

Received 5 November 2014; revised 26 November 2014; accepted 18 December 2014

Copyright @ 2015 by author and Scientific Research Publishing Inc.

This work is licensed under the Creative Commons Attribution International License (CC BY). http://creativecommons.org/licenses/by/4.0/

(c) (1) Open Access

\begin{abstract}
Recently, some specificities of hydrothermal synthesis have been discussed by Avvakumov, Senna and Kosova, emphasizing the ability of water to dissolve selected materials at increased temperature and pressure, and suggest that the process is based on self-ionization. The present author proposes an alternative approach based on low-energy electrons generated by processes of mechanical action (mechanical activation). These types of reactions encompass both mechanochemistry and tribochemistry. Mention wise is that tribochemical reactions are distinct from those of thermochemical reactions. G. Kaupp considers mechanochemistry as mechanical breakage of intramolecular bonds by external force. Sakaguchi et al. introduced the concept of mechano-anionradicals (MARs) generation process in the polymer mechanical degradation via two types of carbon-carbon ( $\mathrm{C}-\mathrm{C}$ ) bond cleavage, homogeneous and heterogeneous. Based on the negative-ionradical-action-mechanism (NIRAM) approach, this paper proposes a novel mechanism which eliminates the heterogeneous $\mathrm{C}-\mathrm{C}$ bond splitting. It is evidenced that both the proposed alternative mechanism and the substitution of the heterogeneous $\mathrm{C}-\mathrm{C}$ bond splitting are possible.
\end{abstract}

\section{Keywords}

Bond Cleavage, Hydrothermal Synthesis, Mechanochemistry, Tribochemistry, NIRAM

\section{Introduction}

In the broad range of mechanochemical terminology, there are many known and widely used definitions of mechanochemistry [1]-[4]. Reviews on mechanochemistry [5]-[7] show Matthew Carey Lea as the first systematic researcher on the chemical effects of mechanical action. Work [8] indicates that mechanochemistry and tribochemistry might be compared with the terms physical chemistry and chemical physics. In the latter term physics is first and chemistry second. In tribochemistry, friction (tribos) is the first. Here tribochemistry (organic mechanochemistry) is considered as the subset of mechanochemistry (inorganic mechanochemistry). The difference between mechanochemistry and tribochemistry is formal, as compared with chemical physics and physical chemistry. 
As mechanics includes friction, tribochemistry should be included in mechanochemistry. Mechanochemical reactions are clearly distinct from those of thermochemical ones. To initiate thermochemical reactions an adequate heat amount has to be supplied to overcome the activation energy [8]. Mechanical interaction of a solidsolid enables chemical reactions to be initiated by lower activation energy than regular thermochemical reactions.

Recent review article on the historical development of mechanochemistry [9], shows and discusses themechanically induced self-propagating reaction (MSR). In that paper, the current knowledge on MSR is reviewed from both experimental and theoretical points of view. Examples of specific phenomena are discussed. It also was stated that the mechanism of MSRs is extremely complex and suggested to combine adequate models with systematic empirical studies. Such approach must generate a way to better understanding of MSR processes.

Present mechanochemistry takes into account physical chemistry and chemical physics. Other specific research works [10]-[12] provide unique information on mechanochemistry and mechanical bond-cleavage. Accordingly, the preparation of co-crystals via mechanochemistry combines the quest for clean and green processes. On the other hand, the question of exactly which processes are the subjects of mechanochemistry is still debated; as new areas of science and technology discover the possibilities offered by mechanical treatment. Therefore, it is necessary to periodically re-consider fundamental notions of mechanochemistry. The most important development of the past several years was the increasing use of mechanical activation in organic

Heterogeneous C-C bond cleavage of solid polymer, produced by mechanical fracture, as demonstrated by Sakaguchi et al. [13] [14] combines triboelectricity in polymers with effects of the ionic nature of carbon-carbon bonds in the polymer main chain on charge due to yield of mechano-anions produced by heterogeneous scission of the carbon-carbon bond.

Polymerization of acrylamide (AA) and methacrylamide (MA), initiated by mechanical action (milling), was presented and discussed in detail over 20 years ago [15]. In work [16] the NIRAM approach has been discussed in detail.

\section{Mechanochemistry}

In the broad range of mechanochemical terminology, there are many known and widely used definitions of mechanochemistry. Actually, the term mechanochemistry has been used for over one century. The same is due to the practical application of mechanochemistry. Paper by L. Takacs [1] underlines that volume 42 (2013) of Chemical Society Reviews [2] and the most recent Faraday Discussion on mechanochemistry [3] reflect many of the new developments. Chemical reactions in solids initiated by mechanical action had been considered for a long period of time [4]. Reviews on mechanochemistry [5]-[7] show Matthew Carey Lea as the first systematic researcher on the chemical effects of mechanical action. Work [8] indicates that mechanochemistry and tribochemistry might be compared with terms: physical chemistry and chemical physics. In the latter term physics is first and chemistry second. In tribochemistry, friction (tribos) is the first.

As mechanics includes friction, tribochemistry should be included in mechanochemistry. Mechanochemical reactions are clearly distinct from those of thermochemical ones. To initiate thermochemical reactions an adequate heat amount has to be supplied to overcome the activation energy [8]. Mechanical interaction of a solidsolid enables chemical reactions to be initiated by lower activation energy than regular thermochemical reactions. Recent review article [9] presents historical development of mechanochemistry from experimental and theoretical points of view; examples of specific phenomena are discussed.

Interestingly to note that ten years ago, work [10] made it possible to register mechano transduction (MT) also in live cells with spatiotemporal characterization. It was found that the transmission of mechanically induced activation is the dynamic process that directs signals via the cytoskeleton to spatial destinations. MT is the term concerning action mechanisms by which cells convert mechanical stimulus to chemical activity [11]. It is responsible for physiological processes in the body including, for instance, touch and balance. Generally, the MT mechanism changes mechanical signals either into chemicalor electrical signals. Other specific research work [12] provides unique information on mechanochemistry and mechanical bond-cleavage. The bond breakage increases the solid's activity. The actual energy needed for chemical reactions is lowered by mechanical work [17]. Reactions by low-energy electrons are described in [18]-[20]. Catalyst lowers the activation energy. From this point of view, mechanochemistry is closely linked to mechanocatalysis and, chemistry can be categorized ac- 
cording to how is the energy put into the reaction system. Thermal energy is known as a source triggering chemical reactions. Photon is another type of energy which brings about photochemical reactions. The energy of photon is determined by the wavelength of incident light. Chemical reactions are also enhanced by the electric potential. Thus, the electric potential and current are measures of the energy input. All these energy types lead to very specific entanglements of mechanochemistry and tribochemistry [21] [22]. Mechanochemistry is to be differentiated from molecular solid-state chemistry, where contacts between micronized molecular solids are created by the mechanical action.

By introducing some of the earliest research works in mechanochemistry, it is possible to show how mechanochemical reactions differ from regular thermochemical ones. It is of note here, that according to paper [7] and information [23], Theophrastus of Eresus demonstrated mechanochemistry already in 315 B.C. Another publication [24] concerns mechanochemistry of advanced materials. However, its mechanism has not yet been accounted for. Paper by Takacs [25] also stresses that Carey-Lea showed that HgCl sublimates when heated and decomposes under friction. AgCl melts undecomposed when heated, but it decomposes under friction. Recent Takacs' review paper [25] provides very detailed information relating to the history of mechanochemistry starting with prehistoric times, when reactions were initiated during grinding and rubbing accidentally. It also includes the main developments until the presently achieved results.

Mechanochemistry might also be considered as a sustainable and ecological technology, mechanical energy can be applied by using a simple ball mill mechanical system, leading to a strain in the bulk after removal material from the mill. Very detailed review publications [8] [26] [27] include a wide range of industrial applications of mechanochemistry and underline the need for sustainability brought about by the Kyoto Treaty and the increasing global demand for products leading to an increase in sustainable manufacturing processes. Such processes and/or new technologies can lower environmental demands. Improved sustainability can be realized in the form of reduced energy use, less organic solvents, better selectivity and reduced waste.

Another well specified study [28] presents several advantages of mechanochemical technology, such as simple process, ecological safety and the possibility of obtaining a product in the metastable state. Therefore, it gives an overall review of the mechanochemistry applications in waste management. Interestingly to note that based on that study, the modification of fly ash and asbestos containing wastes (ACWs) can be achieved by mechanochemical technology (MCT). Additionally, MCT provides with a prospective application in pollution remediation along with waste management. Hazardous metal oxides can be transformed into easily recyclablesulfide by mechanochemicalsulfidization; the waste plastics and rubbers, which are usually very difficult to be recycled, can also be recycled by mechanochemical technology [29]. The importance of waste-free mechanochemical synthesis and production should also be mentioned.

On the other hand, the question of exactly which processes are the subjects of mechanochemistry is still debated as new areas of science and technology discover the possibilities offered by mechanical treatment. Therefore, it is necessary to periodically re-consider fundamental notions of mechanochemistry. The mostimportant development of the past several years was the increasing use of mechanical activation in organic chemistry, particularly in organic synthesis. While high-energy milling is used to break primary bonds, lower energy is used to facilitate solvent-free reactions and to prepare co-crystals.

\section{Goals of the Article}

The first goal proposes to substitute the self-ionization process [30] [31] in Equations (1) and (2)

$$
\begin{aligned}
& 2 \mathrm{H}_{2} \mathrm{O} \rightarrow \mathrm{H}_{3} \mathrm{O}^{+}+\mathrm{OH}^{-} \\
& \mathrm{H}_{2} \mathrm{O}+\mathrm{e}^{-} \rightarrow \mathrm{H}^{+}+\mathrm{OH}^{-}
\end{aligned}
$$

by action of low-energy electrons in Equation (3)

$$
\mathrm{H}_{2} \mathrm{O}+\mathrm{e}^{-} \rightarrow \mathrm{H}^{\bullet}+\mathrm{OH}^{-}
$$

The second goal verifies mechano-anion-radicals (MARs) concept of the polymermechanical degradation via two types of carbon-carbon (C-C) bond cleavage, homogeneous and heterogeneous.

\section{Discussion}

Theoretical studies suggest that a formulation concerning triboelectricity is possible, anyway the formulation of 
a satisfactory theory to account for the triboelectricity of polymers has yet to be established [13] [14]. It was emphasized that the frictional action between two polymers should induce macroscopic fracture of the polymers and simultaneously cut of carbon-carbon (C-C) bonds of the polymer main chain on the frictional surface proceeds [13].

Tetra Cya No Ethylene (TCNE) molecules are here of specific importance. The TCNE compound, having an electron affinity of $2.88 \mathrm{eV}$, attracts an electron from the ME, produced by heterolytic $\mathrm{C}-\mathrm{C}$ bond cleavage in a polymer main chain, producing TCNE. It was postulated that the polymer fractured with TCNE in the dark at 77 $\mathrm{K}$ under vacuum generates free radicals and positively plus negatively charged ions. Mixing by vibro milling was applied to generate homogeneous radicals and heterogeneous ions [13]. Then, it was assumed that UV irradiation in TCNE presence produced MARs. After the milling, the fractured sample was dropped into the ESR (Electron Spin Resonance) sample tube under vacuum in the dark at $77 \mathrm{~K}$, and irradiated using an IR lamp (visible photon energy range was 1.24 - 3.10). The situation is reflected in Figure 1.

Figure 2 demonstrates the proposed novel alternative mechanism based on the negative-ion-radical approach (NIRAM). It excludes generation of positively charged mechanical ions. This process produces polymer mechano-anions being combined with the polymer triboelectricity phenomenon caused by mechanical scission of the polymer main chain on the mechanically activated surfaces by contact friction.

The energy of electrons emitted from polymers amounts to scores of kilo electron-volts (keV), with the emission itself being a lengthy, slowly decaying process; such electrons are called mechano-electrons [13]. The electronic theory proposes an electron transfer across the interface of contacting bodies with different electronic and structures [15]. Work [16] presents the NIRAM approach. Figure 2 demonstrates proposed novel alternative mechanism based on the negative-ion-radical approach (NIRAM).

The novel alternative mechanism excludes production of positively charged heterogeneous ions suggested by Sakaguchi's research group [13] [14]. This process produces polymer mechano-anions being combined with the polymer triboelectricity phenomenon caused by mechanical scission of the polymer main chain on the mechanically activated surfaces by contact friction. Friction between dielectrics results in the production of electric charge. The energy of electrons emitted from polymers amounts to scores of $\mathrm{keV}$, with the emission itself being a lengthy, slowly decaying process; such electrons are called mechano-electrons [17].

According to the present author knowledge, major work related to the generation process of polymer mechano-anions has been performed by very special Sakaguchi's research group [13] [14]. Both papers list adequate references along with the statement saying "a number of quantitative and theoretical studies suggest that a formulation concerning triboelectricity is possible", anyway the formulation of a satisfactory theory to account for the triboelectricity of polymers has yet to be established. Here it should be noted that mechanochemically

To generate free radicals and positivly plus negatively charged ions vibromilling (mixing) was used.

$$
\begin{gathered}
\mathbf{R}-\mathbf{R} \rightarrow \mathbf{2} \mathbf{R}^{\cdot} \quad \text { Homogeneous } \\
\mathbf{R}-\mathbf{R} \rightarrow \mathbf{R}^{\ominus}+\mathbf{R}^{\oplus} \text { Heterogeneous }
\end{gathered}
$$

Then, it was assumed \& suggested that UV irradiation in the TCNE presence produced mechano-anion-radicals.

$$
\begin{gathered}
\mathbf{R}^{-}+\mathbf{T C N E} \stackrel{\text { mixing in the dark }}{\longrightarrow} \mathbf{R}^{\bullet}+\mathbf{T C N E}^{\bullet-} \\
\mathbf{R}^{-}+\mathbf{T C N E} \stackrel{\text { photoirradiation }}{\longrightarrow} \mathbf{R}^{\bullet}+\mathbf{T C N E}^{\bullet} \text { - }
\end{gathered}
$$

Figure 1. Generation of free radicals, ions and mechano-anionradicals (MARs) based on works of Sakaguchi's research group.

The present author's alternative mechanism is as follows:

$$
\text { TCNE + e } \rightarrow \text { TCNE }^{*}
$$

and thus, accordidng to the NIRAM approach, the electron attachment to TCNE replaces the heterogeneous $\mathbf{C}-\mathbf{C}$ bond cleavage shown in Fig. 1

Figure 2. Replacing C-C bond scission by the NIRAM approach. 
initiated polymerization of acryl- and methacrylamides [15] adds well to both mechanochemistry and tribochemistry, from the view point of tribopoly merization mechanisms. The influences of temperature and duration had been examined. The polymers were characterized in detail and, an anion-radical mechanism was proposed.

Vibratory milling was applied to test the process without polymerization initiators [15]. Tested monomers were purified by recrystallization (from benzene) and then were introduced together with the grinding bodies (balls of $9 \mathrm{~mm}$ diameter) in the reaction vessel. Grinding was performed with pure nitrogen. After milling, products were separated from the grinding bodies and, the unreacted monomer was removed by dissolving the sample in acetone. The remained polymer was dried.

The filtered products were evaporated in the atmosphere and the residual solid was dried to constant weight.

Effect of the grinding duration on the conversion was also studied (see Figure 3). It is of note that the polymerization is slow between 24 and $72 \mathrm{hr}$. Then there is an acceleration and the maximum is reached at $96 \mathrm{hr}$.

For longer durations, the conversion decreases.

The shape of the conversion time curve is typical for mechanochemically activated polymerizations.

This is found for all monomers previously studied by Oprea research group [15] [32] [33].

Figure 4 demonstrates inhibitors effect on the conversion rate. The temperature influence on the mechanical activation of AA depicts Figure 5.

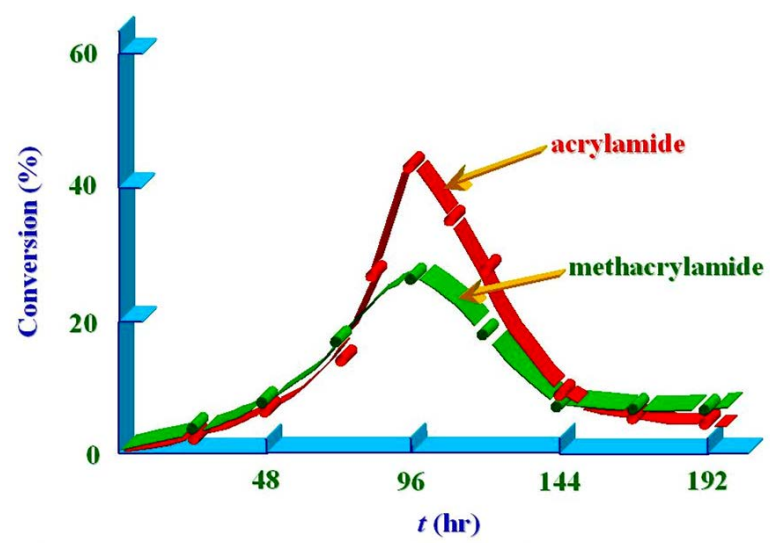

Influence of grinding duration on the conversion: acrylamide; methacrylamide.

Figure 3. Influence of grinding duration on the conversion (\%) of acrylamide (AM) and methacrylamide [15].

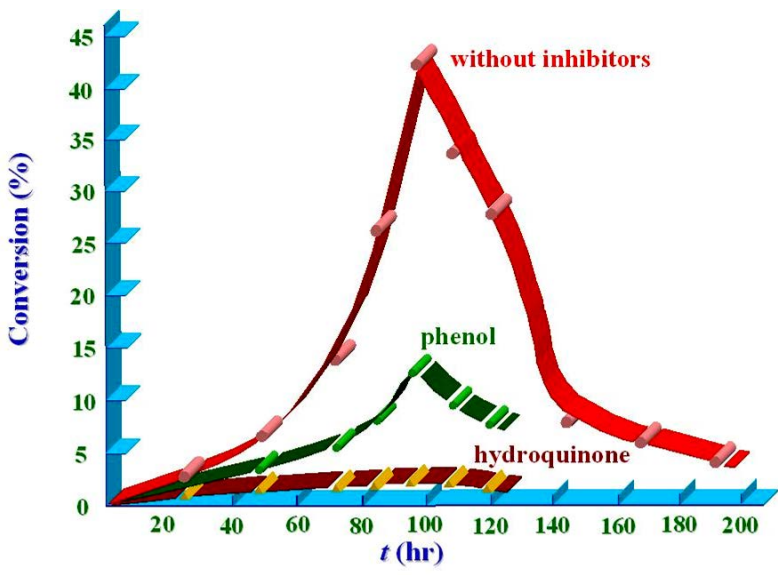

Influence of some inhibitors on mechanochemical polymerization of acrolamide: without inhibitors; phenol; hydroquinone.

Figure 4. Effect of inhibitors on conversion of mechanically initiated polymerization during the grinding time on the conversion rate (\%) [15]. 


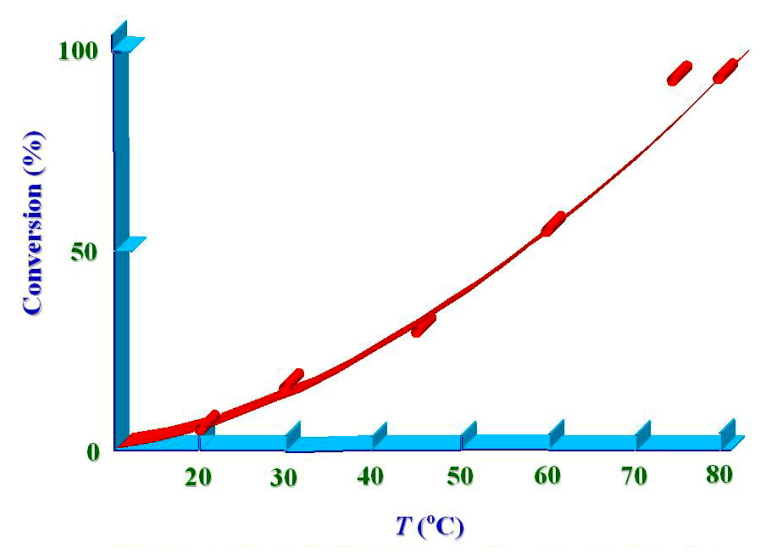

Figure 5. Temperature influence on the conversion for acrylamide (AA) polymerization [15].

Summarizing extensive research results presented in paper [15] the following information is of importance.

1) The vibratory milling of acrylamide (AA) and methacrylamide (MA) solid monomers leads to initiation of the polymerization process.

2) Mechanism of the polymerization is controlled by a radical mechanism and, it is characterized by auto-acceleration.

\section{Summary Remarks}

It has been demonstrated that the self-ionization process expressed by the following equations:

$$
\begin{aligned}
& 2 \mathrm{H}_{2} \mathrm{O} \rightarrow \mathrm{H}_{3} \mathrm{O}^{+}+\mathrm{OH}^{-} \\
& \mathrm{H}_{2} \mathrm{O}+\mathrm{e}^{-} \rightarrow \mathrm{H}^{+}+\mathrm{OH}^{-}
\end{aligned}
$$

can be substituted by alternative approach, based on low-energy electrons generated by processes of mechanical action/activation.

The alternative approach is depicted below

$$
\mathrm{H}_{2} \mathrm{O}+\mathrm{e}^{-} \rightarrow \mathrm{H}^{\bullet}+\mathrm{OH}^{-}
$$

$\mathrm{H}_{2} \mathrm{O}+\mathrm{e}^{-} \rightarrow \mathrm{OH}^{-}+$Positively charged site (Pcs) ${ }^{+}$.

$\mathrm{Pcs}^{+}+\mathrm{e}^{-} \rightarrow$ Neutral surface site $\left(\mathrm{Nss}^{0}\right)$.

$\mathrm{Pcs}^{+}$sites are produced by the mechanical action/activation processes.

Accordingly, the former Equation (2) $\mathrm{H}_{2} \mathrm{O}+\mathrm{e}^{-} \rightarrow \mathrm{H}^{+}+\mathrm{OH}^{-}$can be substituted by reaction $\mathrm{H}_{2} \mathrm{O}+\mathrm{e}^{-} \rightarrow \mathrm{H}^{\bullet}+\mathrm{OH}^{-}$producing $\left(\mathrm{Nss}^{0}\right)$.

Such reactions relate to both mechanochemistry and tribochemistry.

\section{Conclusions}

1) The goals of this work are achieved. None evidence has been found for generation of positively charged ions. Generation of only free radicals and mechano-anion-radicals (MARs) was demonstrated.

2) The developed novel alternative mechanism is based on the negative-ion-radical action mechanism (NIRAM).

3) The novel mechanism excludes generation of positively charged mechanical ions presented in references [13] [14].

\section{References}

[1] Takacs, L. (2014) What Is Unique about Mechanochemical Reactions? Acta Physica Polonica A, 126, 1040-1043.

[2] Urakaev, F.K. (2007) Mechanodestruction of Minerals at the Crack Tip (Overview): 1. Experiment. Physics and Chemistry of Minerals, 34, 351-361. 
[3] Faraday Discussion 170 (2014) Mechanochemistry: From Functional Solids to Single Molecules. Montreal, May 21-23.

[4] Carey-Lea, M. (1893) On Endothermic Reactions Effected by Mechanical Force. Philosophical Magazine, 36, 350-351.

[5] Takacs, L. (2003) M. Carey Lea. The Father of Mechanochemistry. Bulletin for the History of Chemistry, 28, 26-34.

[6] Takacs, L. (2003) M. Carey Lea, the First Mechanochemists. Journal of Materials Science, 39, 4987-4993.

[7] Takacs, L. (2000) The First Documented Mechanochemical Reaction? Journal of Metals, 52, 12-13.

[8] Kajdas, C. (2013) General Approach to Mechanochemistry and Its Relation to Tribochemistry. In: Pihtili, H., Ed., Tribology in Enginering, InTech, Chapter 11. http://dx.doi.org/10.5772/50507

[9] Takacs, L. (2013) M. Carey Lea, the First Mechanochemist. Journal of Materials Science, 39, 4987-4993

[10] Wang, Y., Botvinick, E.L., Zhao, Y., Berns, M.W., Usami, S., Tsien, R.Y. and Chien, S. (2005) Visualizing the Mechanical Activation of Src. Nature, 434, 1040-1045. http://dx.doi.org/10.1038/nature03469

[11] Katsumi, A., Orr, A.W., Tzima, E. and Schwartz, M.A. (2003) Integrins in Mechanotransduction. Journal of Biological Chemistry, 279, 12001-12004. http://dx.doi.org/10.1074/jbc.R300038200

[12] Braga, D., Maini, L. and Grepioni, F. (2013) Mechanochemical Preparation of Co-Crystals. Chemical Society Reviews, 42, 7638-7648. http://dx.doi.org/10.1039/c3cs60014a

[13] Sakaguchi, M. and Kashiwabara, H. (1992) A Generation Mechanism of Triboelectricity Due to the Reaction of Mechanoradicals with Mechanoions Which Are Produced by Mechanical Fracture of Solid Polymer. Colloid and Polymer Science, 270, 621-626. http://dx.doi.org/10.1007/BF00654038

[14] Sakaguchi, M., Miwa, Y., Hara, S., Sugino, Y., Yamamoto, K. and Shimada, S. (2004) Triboelectricity in Polymers: Effects of the Ionic Nature of Carbon-Carbon Bonds in the Polymer Main Chain on Charge Due to Yield of MechanoAnions Produced by Heterogeneous Scission of the Carbon-Carbon Bond by Mechanical Fracture. Journal of Electrostatics, 62, 35-50. http://dx.doi.org/10.1016/j.elstat.2004.04.003

[15] Simionescu, Cr.I., Oprea, Cl.V. and Nicoleanu, J. (1983) Mechanochemically Initiated Polymerization-5. Polymerization by Vibratory Milling of Acrylamide and Methacrylamide. European Polymer Journal, 19, 525-528. http://dx.doi.org/10.1016/0014-3057(83)90204-5

[16] Kajdas, C. (1994) Importance of Anionic Reactive Intermediates for Lubricant Component Reactions with Friction Surfaces. Lubrication Science, 6, 203-228. http://dx.doi.org/10.1002/ls.3010060302

[17] Kaupp, G. (2009) Mechanochemistry: The Varied Applications of Mechanical Bond-Breaking. The Royal Society of Chemistry. CrystEngComm, 11, 388-403. http://dx.doi.org/10.1039/b810822f

[18] Kajdas, C. (1983) On a Negative-Ion Concept of EP Action of Organo-Sulfur Compounds. ASLE Transactions, 28, 21-30. http://dx.doi.org/10.1080/05698198508981590

[19] Kajdas, C. (1985) About a Negative-Ion Concept of the Antiwear and Antiseizure Action of Hydrocarbons during Friction. Wear, 101, 1-12. http://dx.doi.org/10.1016/0043-1648(85)90208-X

[20] Kajdas, C. (1987) About an Anionic-Radical Concept of the Lubrication Mechanism of Alcohols. Wear, 116, $167-180$. http://dx.doi.org/10.1016/0043-1648(87)90231-6

[21] Hsu, S.M., Zhang, J. and Yin, Z. (2002) The Nature and Origin of Tribochemistry. Tribology Letters, 13, 131-139. http://dx.doi.org/10.1023/A:1020112901674

[22] Boldyrev, V.V. and Tkacova, K. (2000) Mechanochemistry of Solids: Past, Present, and Prospects. Journal of Materials Synthesis and Processing, 8, 121-132. http://dx.doi.org/10.1023/A:1011347706721

[23] Carey-Lea, M. (1893) XXXVI. Note on the Calculation of Correlation between Organs. Philosophical Magazine Series 5, 36, 350-351. http://dx.doi.org/10.1080/14786449308620487

[24] Baláž, P., Choi, W.S., Fabián, M. and Godočíková, E. (2006) Mechanochemistry in the Preparation of Advanced Materials. Acta Montanistica Slovaca, 11, 122-129.

[25] Takacs, L. (2013) The Historical Development of Mechanochemistry. Chemical Society Reviews, 42, 7649-7659. http://dx.doi.org/10.1039/c2cs35442j

[26] James, S.L., Adams, C.J., Bolm, C., Braga, D., Collier, P., Friščić, T., et al. (2012) Mechanochemistry: Opportunities for New and Cleaner Synthesis. Chemical Society Reviews, 41, 413-447. http://dx.doi.org/10.1039/c1cs15171a

[27] Beyer, M.K. and Clausen-Schaumann, H. (2005) Mechanochemistry: The Mechanical Activation of Covalent Bonds. Chemical Reviews, 105, 2921-2948. http://dx.doi.org/10.1021/cr030697h

[28] Fujiwara, K. and Komatsu, K. (2002) Mechanochemical Synthesis of a Novel C 60 Dimer Connected by a Silicon Bridge and a Single Bond. Organic Letters, 4, 1039-1041. http://dx.doi.org/10.1021/ol025630f 
[29] Guo, X., Xiang, D., Duan, G. and Mou, P. (2010) A Review of Mechanochemistry Applications in Waste Management. Waste Management, 30, 4-10. http://dx.doi.org/10.1016/j.wasman.2009.08.017

[30] Litvin, B. and Popolitov, V. (1984) Hydrothermal Synthesis of Inorganic Compounds. Nauka, Moskva.

[31] Avvakumov, E., Senna, M. and Kosova, N. (2001) Soft Mechanochemical Synthesis. Kluwer Academic Publishers, Boston.

[32] Oprea, C.V. and Popa, M. (1980) Mechanochemically Initiated Polymerization-II. Influence of Some Factors on the Mechanochemical Homopolymerization of Acrylonitrile by Vibratory Milling. Die Angewandte Makromolekulare Chemie, 90, 13-22.

[33] Oprea, C.V. and Popa, M. (1980) Mechanochemically Initiated Polymerizations. Characterization of Poly(acrylonitrile) Mechanically Synthesized by Vibratory Grinding. Die Angewandte Makromolekulare Chemie, 92, 73-88. 
Scientific Research Publishing (SCIRP) is one of the largest Open Access journal publishers. It is currently publishing more than 200 open access, online, peer-reviewed journals covering a wide range of academic disciplines. SCIRP serves the worldwide academic communities and contributes to the progress and application of science with its publication.

Other selected journals from SCIRP are listed as below. Submit your manuscript to us via either submit@scirp.org or Online Submission Portal.
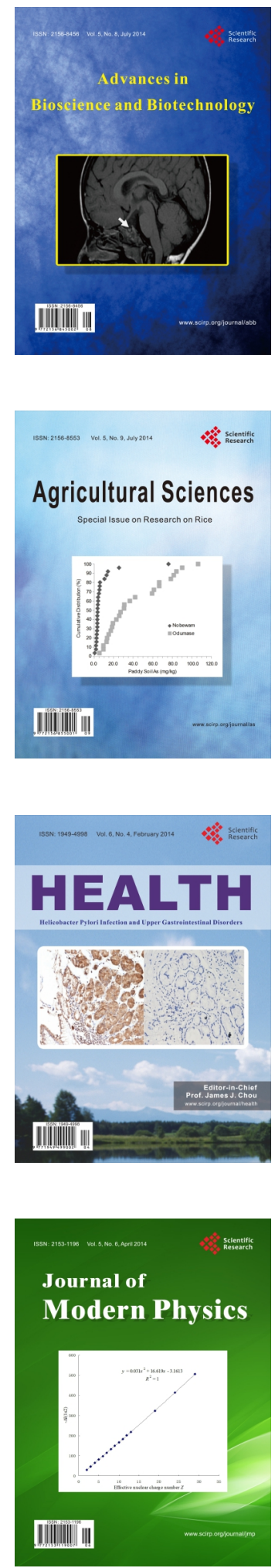
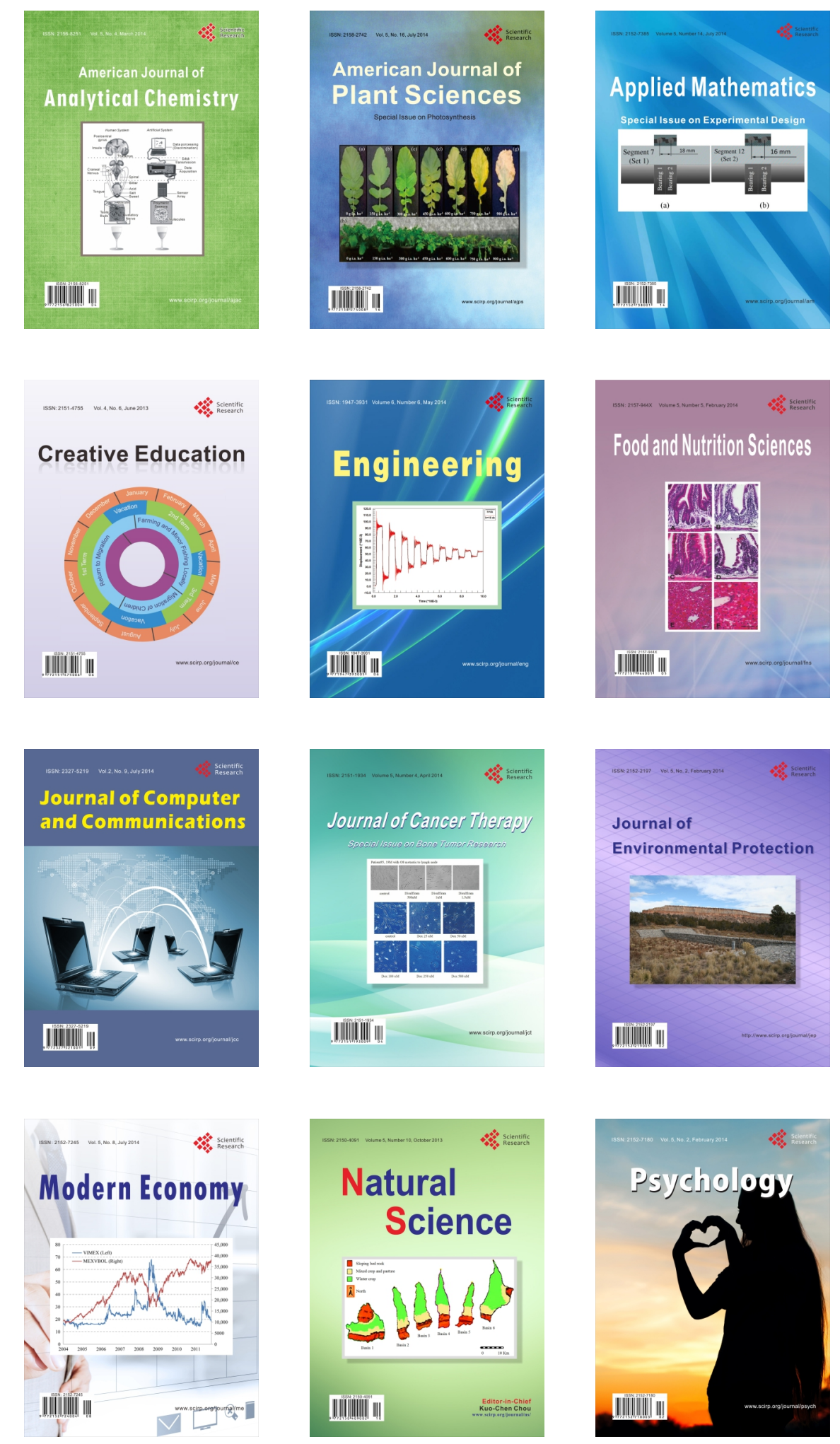